\title{
Considering the concept of recipience in student learning from a modified Bernsteinian perspective
}

Kinchin, I.M., Winstone, N.E., \& Medland, E.

Department of Higher Education, University of Surrey, Guildford, Surrey, GU2 7XH

Contact: $\underline{\text { i.kinchin@surrey.ac.uk }}$

\section{Biographies}

Ian Kinchin is Professor of Higher Education at the University of Surrey. He is engaged in the professional development of academic staff, while undertaking research into university pedagogy and the application of Novakian concept mapping. He is currently developing a model for academic development that is framed by the concepts of pedagogic frailty and resilience.

Naomi Winstone is a Reader in Higher Education at the University of Surrey where she is Head of Department of Higher Education. Her research interests focus on cognition and learning, and the application of psychological theory to educational contexts. She is a Senior Fellow of the Higher Education Academy and a National Teaching Fellow.

Emma Medland is a Lecturer in Higher Education at the University of Surrey. She is a Senior Fellow of the Higher Education Academy and has been a Lecturer for 11 years, working at Surrey and King's College London. She is currently the Programme Director of the MA in Higher Education and manages the provision of Continuing Professional Development workshops to support the pedagogic development of academic staff and those involved in supporting learning across the institution.

ORCID

Ian Kinchin http://orcid.org/0000-0001-5425-4688

Naomi Winstone http://orcid.org/0000-0001-8157-8274

Emma Medland http://orcid.org/0000-0003-0479-4138

\section{Acknowledgement:}

Our sincere thanks to Karen Gravett and Kieran Balloo for their constructive comments on drafts of this paper. 


\title{
Considering the concept of recipience in student learning from a modified Bernsteinian perspective
}

\author{
Kinchin, I.M., Winstone, N.E., \& Medland, E.
}

\begin{abstract}
The concept of recipience is emerging within the literature as a useful idea to inform our understanding of student engagement with feedback. In this paper the applicability of the concept of recipience is broadened from its origins in the literature on student feedback to consider its role in developing student knowledge structures that are more receptive to development. This will promote cumulative/meaningful learning that is required to construct professional knowledge. By drawing on Legitimation Code Theory, and visualising the morphology of target knowledge structures in relation to their position on the semantic plane (of semantic gravity vs. semantic density), a fresh perspective is offered to inform student learning that can suggest ways of enhancing the quality of student learning. This is achieved by explicitly enabling the construction of a more coherent perspective of the knowledge terrain generated by complex curricula.
\end{abstract}

Key words: Knowledge recipience, Legitimation Code Theory, concept mapping, semantic waves, powerful knowledge, professional knowledge.

\section{Introduction}

The development of students' learning, and particularly their critical thinking skills, are often placed at the centre of discussions about the enhancement of higher education. However, the practicalities of this are often reduced to tinkering with elements of the instructional discourse (the processes and mechanisms that help to manage teaching) rather than addressing the values and beliefs that guide practice (the so-called regulative discourse Bernstein, 1999; 2000). In this paper we focus on the central issue of transformative learning by considering the fundamental question of the structure of the knowledge that is being created. This is based on the assumption that only when staff and students appreciate how knowledge should be optimally constructed (and why), is there a chance that learning will actually happen - after which the related instructional issues will fall into place to support this process.

The goal of meaningful/cumulative learning among students transcends other short-term, politically-motivated policy drivers in higher education. The promotion of learning is considered to be a shared aim among those working in education, with educators urging the need for pedagogic practice to have 'positive effects that extend 
beyond the exact conditions of initial learning by enabling students to build on previous understandings and transfer what they learn into future contexts.' (Maton, 2013: 8). Universities are often pushed towards a consideration of learning that is framed by instructional discourses (such as that surrounding employability, e.g. O'Leary, 2017; Zajacova et al, 2019) that are driven by a metrics-led, managerial focus rather than through consideration of the more messy assemblage created by the discourses of teaching and classroom practice (e.g. Mooney Simmie et al, 2019). This paper aims to add clarity to those messy discourses by looking at the key concept of recipience in student learning. As meaningful learning is effortful (e.g. Novak, 2010), and teachers need to ensure that they guide students to focus that effort profitably on approaches that optimise the development of expert knowledge structures, and that will serve them well beyond their formal education.

\section{The concept of recipience}

The concept of recipience is drawn from the literature on feedback (e.g. Winstone et al, 2017). In an attempt to bring meaning to the concept of student engagement in the context of feedback processes, Winstone et al. (2017) conducted a systematic review of the literature on the topic. In so doing, they termed meaningful engagement with feedback 'proactive recipience', defined as 'a form of agentic engagement that involves the learner sharing responsibility for making feedback processes effective' (Winstone et al., 2017, p.17). Proactive recipience can be further broken down to incorporate students' active sense-making of feedback information, and reasoned decisionmaking for action upon comments (Winstone \& Carless, 2019).

When explored further, the distinction between simplistic reception and this more agentic concept of recipience reveals many parallels to learning processes beyond the domain of feedback. Winstone and Carless (2019) presented an analogy to illustrate the difference between these two levels of engagement. An athlete, upon being provided with developmental advice by their coach, takes the critique on board and keeps it in mind in their next training session. Whilst the athlete has processed the feedback, they have not engaged in sense-making nor considered how best to enact the advice. If they, for example, choose to video-record their next training session, and then watch it back to critique their own performance, or seek further advice from their coach or a fellow athlete, they are actively deconstructing the meaning of the comments, self-appraising their progress, and seeking further feedback. It is actions such as these that elevate surface engagement with feedback to the level of proactive recipience (Winstone \& Carless, 2019). 
It becomes apparent, then, that crucial to the concept of recipience is learner agency. Recipience is an active process; in Piagetian terms, it requires accommodation not assimilation (Piaget, 1963). Recipience depends upon the application and use of information, not merely regurgitation. Recipience requires the asking of questions, active seeking of feedback, interrogating the meaning of comments, deconstructing and reconstructing advice, and the synthesis of multiple feedback processes. In learning, it is not the passive reception of information that facilitates transformative learning, but processes of sense-making, deconstruction, reconstruction and synthesis with existing knowledge that facilitates such effects.

The recipience of new knowledge and the recipience of feedback on the assessed demonstration or rehearsal of that knowledge are, therefore, overlapping events, both of which involve interaction with students' evolving knowledge structures. However, feedback is often discussed in the literature as if it is a distinct operation separated from learning. Rather than being a part of learning, feedback is described as being fundamental to learning, with traditional practices in HE considered to be 'not fit for purpose' (Carless et al., 2011: 395). The potential benefits of feedback are compelling, yet its 'practical failure' (O'Donovan et al., 2016: 945) highlights feedback as an area of concern internationally (Medland, 2016; Nicol, 2010). Evidence indicates the stubborn sector-wide misconception that only post-assessment written comments, that provide a physical artefact for examination, constitute feedback (Winstone \& Pitt, 2017). Consequently, verbal feedback skills are underdeveloped as HE fails to prepare students (and teachers) to engage with this rich and abundant, yet more difficult to capture, form of feedback (Black \& McCormick, 2010). Greatest exposure to, and engagement with feedback, takes the form of verbal interactions within taught sessions, yet this is an overlooked area of research, primarily because it is perceived as part of the dialogue of learning and teaching (Tai et al., 2018). In other words, the distinction between 'oral feedback' and 'classroom dialogue' is blurred, and possibly irrelevant. This is particularly so if we consider the need for feedback to offer more than the transmission of post-assessment guidance on 'local repairs in the assignment at hand,' and to move towards a dialogic partnership between students and teachers in which 'permanent revision to [students'] knowledge networks' that could be used in other contexts is central (Nicol, 2013: 36). This shift in perspective from the old transmission-based paradigm, to the new dialogic-based paradigm (Carless, 2015) positions 'feedback' as just part of the dialogue of learning rather than a separate artefact with special status.

In line with this shift, in this paper we consider the concept of recipience to have significance in the wider teachinglearning arena (i.e. beyond the confines of the discourses of feedback and assessment). Whether during a feedback episode or during a teaching episode (such as a lecture or a tutorial) students need to be able to demonstrate 
recipience of information in order to develop expert, professional knowledge structures. We integrate psychological and sociological perspectives to propose that different knowledge structures (as depicted by morphologically distinct concept maps; Kinchin et al., 2000) are likely to exhibit different levels of recipience, i.e. different levels of receptivity to the accommodation of new or additional knowledge. In particular:

a) Linear knowledge structures (chains) will exhibit 'low recipience', in that they do not support or encourage the formation of additional links to newly acquired information (i.e. reflecting a process of assimilation). See Figure 1, lower left quadrant.

b) Networked knowledge structures will exhibit 'high recipience', in that they are receptive to elaboration and are likely to support the development of new links (i.e. reflecting a process of accommodation). See Figure 1, upper right quadrant.

\section{[FIGURE 1 HERE]}

Figure 1 offers a visual synthesis of a number of concepts that we have integrated from the sociological and psychological traditions of educational research. The knowledge structures that are indicated as concept map morphologies, draw on Novak (2010) and the way in which knowledge may be viewed. These structures have been shown to be indicative of, for example, meaningful or rote learning as well as the theoretical or practical disposition of the learning. This overlaps with Bernstein's view of knowledge structures (Bernstein, 1999) and the way they can be mapped, for example, according to their relation to context (Maton, 2014a). Key to both of these views of knowledge is the dynamic process that underpins learning that may be variously described as weaving between different forms, or being transformative of the goal structure. These movements between different states require that knowledge structures are able to invite these movements - by exhibiting recipience.

\section{Knowledge structures and the semantic plane}

Knowledge can be structured in different ways. Practical knowledge tends to occur as linear strings of information that can be activated to address a particular problem, while theoretical knowledge tends to have a more complex structure in which ideas are linked in various directions. The relationship between theoretical and practical knowledge is crucial if students are to be able to apply what they learn in class and not just memorise information in order to pass exams. Bernstein's influential work on knowledge structures (Bernstein 1999; 2000) has been developed as an element of Legitimation Code Theory (LCT) by Maton (2009: 44) as a sociological toolkit to help consider how 'curriculum structures play a role in creating conditions for students to experience cumulative 
learning, where their understandings integrate and subsume previous knowledge, or segmented learning, where new ideas or skills are accumulated alongside rather than build on past knowledge'. Maton's view of the arrangement of different types of knowledge, on what he refers to as the semantic plane (Figure 1) and the application of concept mapping (Novak, 2010) constitute complementary approaches that combine to provide insights into the relative structure of knowledge and the curriculum contexts under which these structures are constructed. The segmented learning described by Maton parallels a surface approach that would result in the serial acquisition of knowledge chains, ultimately leading to cycles of non-learning, in which information is never meaningfully integrated to offer the learner any utility beyond the immediate classroom environment (as described by Kinchin, Lygo-Baker \& Hay, 2008). The cumulative learning referred to by Maton equates to the meaningful learning promoted by Novak (2010) that is typically represented by integrated knowledge networks. Making unambiguous links between these complementary knowledge structures by helping students to make links between theory and practice is a major issue in curriculum design and delivery, and in the development of expertise (Kinchin \& Cabot, 2010; Kinchin, 2013).

When knowledge is depicted as a concept map (Novak, 2010), a number of distinct morphologies have been recognised, each of which exhibit different properties (Kinchin et al, 2000). The 'spoke' structure is usually indicative of novice knowledge (Figure 1, upper left quadrant). This basic structure is usually complemented by simple linking phrases on the connecting arrows that indicate a low level of understanding. These linking phrases that explain the nature of the link are key to revealing the student's level of understanding. The 'chain' structure is indicative of procedural knowledge and is usually acquired as a discrete unit by a process of context-specific rote (or segmented) learning (Figure 1, lower left quadrant). Chains (often associated with practice) are resistant to restructuring unless they are underpinned by a related network of understanding. Chains are derived from networks, but when they are acquired through rote learning, the related network does not 'belong' to the student (i.e. it is the teacher's network that often remains private and hidden). Networks of understanding are often more sophisticated structures in which concepts are linked via a variety of routes and associated with a number of other concepts so that they refer to general principles of a subject (Figure 1, upper right quadrant). The linking phrases within networked maps often employ more sophisticated disciplinary language so that the links add meaning to the concepts and the maps can be described as exhibiting greater explanatory power than the other morphologies (Kinchin, 2016).

The concepts of semantic gravity and semantic density have been developed by Maton (2014) from Bernstein's knowledge structures approach. Semantic gravity (SG) refers to the 'degree to which meaning relates to its 
context' (ibid: 129). This can be relatively stronger (+) or weaker (-) along a continuum from theoretical to practical knowledge. Therefore, a concrete example of something tied to a particular context may be seen to exhibit a stronger semantic gravity (SG+) than a more abstract generalisation derived from it (SG-). The morphology of knowledge structures can be related to the concepts of semantic density and semantic gravity so that typically we find the following relationships:

\section{Morphology}

Spoke
Chain

Network

Chain \& Network

\section{Semantic profile}

SD- SG-

SD- SG+

SD+ SG-

$\mathrm{SD}+\mathrm{SG}+$

\section{Type of knowledge}

Novice

Procedural

Conceptual

Professional

Crucially, the dynamic nature of semantic gravity needs to be recognised so that oscillations between generalised abstractions and concrete examples (i.e. movements between theory and practice) are referred to in terms of

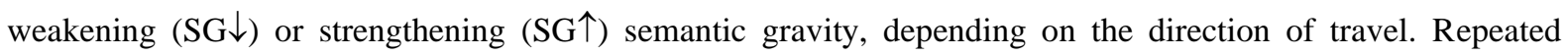
oscillations back and forth in this way are described by Maton as semantic waves or semantic weaving (Figure 2). Semantic density (SD) refers to 'the condensation of meaning' (Maton, 2014, 129) that may be determined by socio-cultural practices, symbols, terms, concepts, phrases, gestures, actions etc. Embedded within specialist texts or practices of a discipline, there are subtle meanings that are recognised by experts in the field, but may be overlooked by novices who fail to appreciate the appropriate cues from what they may see as 'technically heavy' text. Such condensed representations are often seen to form the backbone of discipline-specific writing (e.g. Brookes \& Etkina, 2007). For novices to begin to gain access to the richness of understanding, some 'unpacking' is typically necessary so that students can construct links to parts of the wider body of disciplinary knowledge.

\section{[FIGURE 2 HERE]}

The relative strengths of semantic gravity and semantic density vary independently along continua to form what Maton refers to as a semantic plane - effectively plotting complexity of knowledge against practicality. In Figure 1 the semantic plane has been populated with the typical goal knowledge structures (represented by morphologically distinct concept maps) that are found within each quadrant. Practical knowledge (SD- SG+) relates to the competencies that are often described within the disciplines that are tied to a given context 
(Wheelahan, 2007), and is often summarized as a linear procedure. In some disciplines these are deliberately separated from the underpinning knowledge as something to be assessed in isolation for the purposes of professional recognition (e.g. RCVS (2014) day-one competencies). This is the type of knowledge that is learned in practical exercises which students are subsequently required to link to the theoretical knowledge (SD+ SG-), that they gain from their books and lectures. The successful combination of conceptual and procedural knowledge $(\mathrm{SD}+\mathrm{SG}+)$, may be seen as the mark of professional knowledge in which the links between theory and practice become second nature to the disciplinary expert (Kinchin \& Cabot, 2010). The explicit linking of these knowledges may be one of the core requirements of a curriculum structure (Kinchin, 2016). Where these links are not explicit, it can be seen that students are prevented from acquiring the powerful knowledge that comes from integration of different knowledge types (e.g. Wheelahan, 2007). A trajectory of expertise development has been plotted against the semantic plane by Shay \& Steyn (2016), who see the novice-beginner occupying the top left quadrant and the expert-master occupying the bottom right quadrant of the plane.

The semantic weaving [Figure 2] between the practical knowledge and the theoretical knowledge that Maton considers to be necessary to relate the different knowledges (Maton, 2014b), and so enable the acquisition of powerful knowledge (sensu Young \& Muller, 2013), or development of the expert student (sensu Kinchin, 2016), requires the development of knowledge structures that support recipience of new understanding through meaningful/cumulative learning. By preventing the semantic weaving between practical (procedural) knowledge and theoretical (conceptual) knowledge, the theory-practice gap (T-P G) also creates a block to the student's pathway from novice to professional knowledge.

\section{Inhibition of recipience and semantic weaving}

Different knowledge structures exhibit different levels of recipience. In particular, chains of knowledge have been seen to be inflexible and unreceptive to additions. Whilst construction of a chain may be appropriate for some practical knowledge where entire protocols need to be acquired as discrete units of context-specific understanding (e.g. how to use the equipment to take a patient's blood pressure), such a knowledge structure is not an effective arrangement for theoretical knowledge (e.g. when do you need to take a patient's blood pressure and what do the numbers signify?) that needs to evolve over time and develop multiple perspectives (Kinchin, 2016). Where chains of knowledge are constructed to occupy the 'theoretical knowledge' quadrant of the semantic plane (Figure 3), this is usually an indication of rote learning (Hay, 2007), where acquiring information does not equate to the 
construction of understanding (Kinchin et al, 2008). In summary, there is generally an inverse relationship between linearity and recipience - the greater the degree of linearity within a knowledge structure, the lower the expected level of recipience.

[FIGURE 3 HERE]

Students need to appreciate the bigger picture of the goal knowledge structure in which their current learning needs to be placed. An appreciation that there are gaps to be filled by further learning is likely to promote active information-seeking behaviours that go beyond the mechanics of using library systems to locate particular sources (e.g. Callinan, 2005). This is perhaps why programmatic / synoptic assessment approaches are gaining momentum across the HE sector, as they require programme teams to step outside of the arbitrary fragmentation of the curriculum into modules of assessment and towards the assessment of the overarching aims and learning outcomes or goal knowledge structures of an entire programme (e.g. Heeneman et al., 2015; Jessop \& Tomas, 2017; van der Vleuten et al., 2017).

Maton (2014a: 123) sees weaving across the semantic plane as the key for successful meaningful learning:

A growing number of studies are showing that the key to academic achievement in many subjects lies neither with stronger nor with weaker semantic gravity, but with extending the range of movements between them.....These movements in semantic gravity provide a necessary (though not sufficient) condition for the decontextualization and recontextualization of knowledge and thus the possibility of cumulative knowledge-building and learning.

Evidence that knowledge structures exhibit high or low recipience (i.e. the degree to which structures invite connections with, and accommodation of, new knowledge) can be found in the literature. For example, the visualisation of student learning offered by Hay et al (2008) shows how a student who constructs an inappropriate theoretical knowledge structure with low recipience (typically a chain) is unable to assimilate new information into her understanding, and in that case experienced a collapse in understanding. Returning to the concept of feedback recipience, in a similar vein a student who is not engaging in proactive recipience may well process comments on a surface level and in a way that relates to the specific assessment task, but may not link those comments to their learning in other units or for other tasks. Viewing feedback on individual tasks in isolation is likely to result in a chain-type knowledge structure. Instead, considering the interrelationships between feedback 
information across tasks and settings, whilst also incorporating the everyday dialogic interactions that constitute feedback, is likely to facilitate more complex knowledge structures characteristic of high recipience.

The example from Hay et al (2008) shows what can happen when a student constructs a chain-type knowledge structure that is inappropriate for the upper right (SG-SD+) quadrant of the semantic plane. Unfortunately, this is a rather typical result of a traditional tell 'em and test 'em teaching approach in which an exchange of complete linear chains of information between teacher and student results in non-learning (Kinchin et al, 2008). This pressure to create short-term chains of knowledge for regurgitation in exams is the result of a range of selection pressures that are both teacher-centred (anxiety, lack of experience, a fragmented view of the curriculum, inherited materials) and institution-derived (pressure of work, inappropriate exam regimes, a dominant culture that is resistant to change). Whilst institutions often yield to managerial pressure to concentrate on changing one of these elements (e.g. through teacher development programmes to address "personal contradictions that impede professional development' - Rowe et al, 2003a), the complementary change in institutional culture (e.g. Rowe et al, 2003b) is often more difficult to address.

\section{Theory-Practice Gap}

The theory-practice gap (T-P G), is universally seen as a negative entity (particularly in professional education) in which theoretical and practical knowledges fail to interact in a positive way to contribute to the development of professional knowledge - and hence expertise (Greenway et al, 2019). However, the theoretical knowledge needed to develop expertise can often be structured inappropriately in a curriculum. Typically, the curriculum depicts a linear structure composed of lecture series and lists of topics to be covered, that may be at odds with the disciplinary structure (Kinchin, 2016) - often exacerbated by curriculum documentation (e.g. Nilson, 2007); textbooks (e.g. Paxton, 2007) or by sequences of passive lectures that promote rote learning (Kinchin et al, 2008). This can be amplified by the unbalanced relationship in the division of power between practitioners and academics, the latter generally enjoying more powerful positions as 'knowing' has been rated more highly than 'doing' (Greenway et al, 2019). If we then develop a linear knowledge structure in the theoretical knowledge quadrant on the semantic plane, we have two linear knowledge structures occupying the two sides of the semantic plane (Figure 3). The lack of communication (resulting from linear knowledge structures) between these two quadrants forms a barrier - the theory-practice gap (T-P G). Referring back to our example of taking a patient's blood pressure as a practical example of this, a student would be seen to have two linear knowledge structures if they were competent at using the apparatus and also knew what to do so long as the readings were in the normal 
range. But if the readings were not as expected, the student would have to appreciate the significance of the readings in order to plan a different course of action. As linear knowledge structures tend to be inflexible and resistant to change, we have a 'conceptual stand-off' across the T-P G, with complementary knowledge structures exhibiting low mutual recipience and inhibiting semantic weaving between quadrants, such that closing the gap (as explored by Rolfe, 1996) becomes even more difficult. These structures may be promoted by poor communication of the curriculum or by application of inappropriate learning orientations (e.g. rote learning) by the student - or often both. Van Heuvelen $(1991 ; 894)$ has explained how construction of inappropriate linear knowledge structures indicate that students fail to appreciate the 'conceptual unity' and 'knowledge hierarchy' of the discipline.

Assessment regimes will also play a part in creating this scenario. In their semantic analysis of a chemistry exam paper, Rootman-le Grange and Blackie (2018) have shown that a tendency to test students' understanding using largely context-dependent questions (in which content is located within only one discrete topic area and does not require any additional information in order to be solved) fails to support cumulative knowledge building. By over-emphasising questions that are situated in the lower left quadrant of the semantic plane (SD-, SG+), 'students' ability to abstract concepts from the context in which it is taught is not being assessed' (Rootman leGrange and Blackie, 2018, 489). Ironically, this emphasis may be as a consequence of attempting to stimulate graduate attributes for employability, by trying to provide employment-related contexts to learning. However, this has a negative impact on students' ability to apply this knowledge in subsequent years of study by failing to construct receptive knowledge structures, thereby negating the cumulative learning aim of a spiral curriculum, and forcing students into cycles of non-learning (Kinchin et al, 2008). The T-P G is made worse when inappropriate linear knowledge structures of theory are created as they cannot perform their function of underpinning the chains of procedural knowledge (Kinchin \& Cabot, 2010). Chains need to be derived from networks if they are to support the exhibition of adaptive expertise (Salmon \& Kelly, 2015) so that students can see where procedural information comes from and how it is derived from application of the underlying theory.

\section{What this perspective offers in practice.}

The arguments considered in this paper present two key issues for curriculum development:

1. How do we encourage students to construct appropriate knowledge structures?

2. How do we encourage students to weave productively between knowledge structures? 
In part, the answer to question one appears simple. Students need to be aware of the existence of different knowledges and their relative importance (Kinchin, 2016). Therefore we need to make explicit exemplars available for scrutiny whilst monitoring the development of student knowledge structures by showing them how to view the structure of information as illustrated by concept mapping, or other appropriate tools. This will generate a sense of coherence for teachers and students alike helping them to integrate the dialogue of feedback into the dialogue of learning.

\section{Curriculum coherence}

The expert student has been defined as 'one who recognises the existence and complementary purposes of different knowledge structures, and seeks to integrate them in the application of practice' (Kinchin, 2011: 187). The semantic plane offers a framework to highlight the occurrence of different knowledge structures and their roles in learning. It helps to provide a sense of coherence across the curriculum without losing or masking the diversity of the knowledge involved by presenting a simplistic and misleading 'straight-way course' through a curriculum (Dewey, 1910: 204) that is not representative of the intricacies of the discipline. The visualisation of recipient knowledge structures across the semantic plane (Figure 1) addresses the three required components of an enhanced sense of coherence (Antonovsky, 1987):

- Comprehensibility - the semantic plane provides a structured and predictable framework for knowledge integration so that students can better understand where they are in the knowledge terrain of the curriculum.

- Manageability - by illustrating the nature of the weaving across the plane that students need to undertake towards professional knowledge, a recognisable pathway can be created through the content, so that students have a better idea of what is required of them.

- Meaningfulness - by appreciating the nature of the elements that combine to achieve the goal knowledge structure, the students can see the point of engagement with the content at different points along the journey, so they can understand the point of making effort in their studies.

Application of these components has been seen to contribute to the creation of a positive orientation towards learning (Lindström and Eriksson, 2011). 
Enhanced recipience for meaningful learning: blurring the boundaries of learning and feedback.

The integration of feedback as learning dialogue in the teaching environment, rather than a post-assessment oneoff event, requires a cultural shift that serves to blur the artificial boundaries between assessment, feedback, teaching and learning. Such a shift would require what is currently labelled as 'feedback' to be viewed as integral to the teaching-learning dialogue rather than a post-assessment written bolt-on to the assessment process. Viewed from this perspective, feedback as an integral part of teaching-learning, rather than providing the 'correct answers', would instead provide a window into expertise and its development, and a means of translating or providing access to the pathways towards expert knowledge structures - making explicit the trajectory shown in Figure 2. This is problematic when feedback is piecemeal, on a module-by-module, task-by-task basis, without any opportunity for integration and synthesis. Connecting feedback information to a framework of skills, graduate attributes, or programme learning outcomes means that there is a structure into which students can integrate feedback information, creating cohesion.

If meaningful learning is indeed the goal of higher education, as expressed by Maton (2009), then it would be appropriate for our teaching to promote the development of structures that can facilitate this through the encouragement of proactive recipience of knowledge. This requires that different knowledges that constitute professional practice be constructed as networks of understanding from which chains of practice can be derived. Where chains of practice are derived from chains of understanding (Figure 3) that are inappropriately constructed as a result of rote learning, the student is unlikely to develop the critical or adaptive capacities that professional practice demand. Adaptive capacities are developed from explicitly networked knowledge (Salmon \& Kelly, 2015).

\section{Conclusion}

For students to become expert students (sensu Kinchin, 2016), they first need to become aware that knowledge exists in different forms often providing complementary structures of conceptual and procedural knowledge that need to be accessed iteratively to generate expert understanding (Kinchin \& Cabot, 2010). To encourage the development of active recipience among students and for them to engage in the manipulation of these knowledge structures, students will require explicit cues to focus their attention on to the key features of (and key concepts within) the goal knowledge structure. The visualisation of knowledge structures (depicted as concept maps) facilitates the simultaneous awareness of multiple critical features of the concept. This is likely to ensure an 
overlap between the intended object of learning and the enacted object of learning. By encouraging construction of appropriate knowledge structures to populate each quadrant of the students' semantic plane (Figure 1), we are also increasing the likely overlap with the lived object of learning (Marton and Tsui, 2004), and so increase the transfer of learning to future contexts (Maton 2013). By applying the notion of recipience to the central issue of knowledge development, we are emphasising the need to consider feedback as an integrated component of teaching and part of the dialogue of the classroom, rather than a bolt-on to the learning process that might only happen after the formal learning has occurred.

Where practical and conceptual knowledges remain obscured by the curriculum, the student is forced to incorporate these knowledges into a single structure where theoretical and practical knowledge are forced together to make unhelpful hybrids (Kinchin et al, 2019), in which theory and practice are not able to complement each other. This lacks the utility of explicitly structured expert knowledge (Figure 1, lower right quadrant) as it impedes the development of practice by inhibiting access to conceptual knowledge. For students to generate robust chains of practice (sensu Kinchin \& Cabot, 2010), they need to be aware of the origins of these chains, i.e. how practice is derived from theory. Where chains are acquired from someone else's understanding (by short-term rote learning of textbooks or lecture notes) they will fail to be flexible or adaptable, and will be either memorized or forgotten, but not understood (Kinchin et al, 2008). For this understanding to develop, the chains of practice need to be derived from networks of understanding that have been constructed by the student. This allows purposeful oscillations between theory and practice (Kinchin \& Cabot, 2010), or semantic weaving (Maton, 2014b) that is required in expert practice. These flows between knowledge structures can only occur if they exhibit recipience to new knowledge.

We contend that the addition of visualised knowledge structures to populate the semantic plane provides concrete examples that academics will be able to relate to in their practice. This will support university teachers to make their own semantic waves between practical teaching and the relatively abstract notion of pedagogy to underpin this and inform progress (Kinchin, 2016). This semantic weaving between teaching (SD-, SG+) and pedagogy (SD+, SG-) may provide the necessary conditions needed to overcome the inertia that has so far prevented a theory of differentiated knowledge to translate into a theory of differentiated curricula (Shay, 2013). 


\section{References}

Antonovsky, A. (1987). Unravelling the mystery of health: How people manage stress and stay well. San Francisco, Jossey Bass.

Bernstein, B. (1999) Vertical and horizontal discourse: An essay. British Journal of Sociology of Education, 20(2), $157-173$

Bernstein, B. (2000) Pedagogy, symbolic control and identity. Oxford, Rowman \& Littlefield.

Black, P., \& McCormick, R. (2010). Reflections and new directions. Assessment \& Evaluation in Higher Education, 35, 493-499.

Brookes, D. T., \& Etkina, E. (2007). Using conceptual metaphor and functional grammar to explore how language used in physics affects student learning. Physical Review Special Topics-Physics Education Research, 3(1), 010105 .

Callinan, J.E. (2005) Information-seeking behaviour of undergraduate biology students. Library Review, 54(2), $86-99$.

Carless, D., Salter, D., Yang, M., \& Lam, J. (2011) Developing sustainable feedback practices. Studies in Higher Education, 36(4), 395-407.

Carless, D. (2015) Excellence in university assessment: learning from award-winning practice. Oxon: Routledge.

Dewey, J. (1910) How we think. D.C. Heath \& Co.

Greenway, K., Butt, G. \& Walthall, H. (2019) What is a theory-practice gap? An exploration of the concept. Nurse Education in Practice, 34, 1-6

Hay, D. (2007) Using concept maps to measure deep, surface and non-learning outcomes. Studies in Higher Education, 32 (1): 39-58

Hay, D.B., Kinchin, I.M. \& Lygo-Baker, S. (2008) Making learning visible: the role of concept mapping in higher education. Studies in Higher Education, 33(3): 295 - 311.

Heeneman, S. Pool, A. Schuwirth, L. van der Vleuten, C. Driessen, E. (2015). The impact of programmatic assessment on student learning: theory versus practice. Medical Education. 49(5):487-98.

Jessop, T. \& Tomas, C. (2017) The implications of programme assessment patterns for student learning Journal. Assessment \& Evaluation in Higher Education 42 (6): 990-999.

Kinchin, I.M. (2011) Visualising knowledge structures in biology: discipline, curriculum and student understanding. Journal of Biological Education, 45(4), 183 - 189.

Kinchin, I.M. (2013) Concept mapping and the fundamental problem of moving between knowledge structures. Journal for Educators, Teachers and Trainers, 4(1), 96 - 106.

Kinchin, I.M. (2016) Visualising powerful knowledge to develop the expert student: A knowledge structures perspective on teaching and learning at university. Rotterdam, Sense.

Kinchin, I.M. \& Cabot, L.B. (2010) Reconsidering the dimensions of expertise: from linear stages towards dual processing. London Review of Education, 8(2), 153 - 166.

Kinchin, I.M., Hay, D.B. \& Adams, A. (2000) How a qualitative approach to concept map analysis can be used to aid learning by illustrating patterns of conceptual development. Educational Research, 42(1), 43 -57.

Kinchin, I. M., Lygo-Baker, S., \& Hay, D. B. (2008). Universities as centres of non-learning. Studies in Higher Education, 33(1), 89-103.

Kinchin, I.M., Möllits, A. \& Reiska, P. (2019) Uncovering types of knowledge in concept maps. Education Sciences, 9(2), 131.

Lindström, B. \& Eriksson, M. (2011) From health education to healthy learning: Implementing salutogenesis in educational science. Scandinavian Journal of Public Health, 39(Suppl. 6), 85 - 92. 
Maton, K. (2009) Cumulative and segmented learning: Exploring the role of curriculum structures in knowledgebuilding. British Journal of Sociology of Education, 30(1), 43-57.

Maton, K. (2013) Making semantic waves: A key to cumulative knowledge-building. Linguistics and Education, 24(1), 8-22.

Maton, K. (2014a) Knowledge and knowers: Towards a realist sociology of education. London, Routledge.

Maton, K. (2014b). Building powerful knowledge: The significance of semantic waves. In Rata, E. \& Barrett, B. (Eds.) Knowledge and the Future of the Curriculum (pp. 181-197). Palgrave Macmillan UK.

Marton, F. \& Tsui, A.B.M. (2004) Classroom discourse and the space of learning. Mahwah, NJ, Lawrence Erlbaum Associates.

Medland, E. (2016) Assessment in higher education: drivers, barriers and directions for change in the UK. Assessment \& Evaluation in Higher Education, 41(1): 81 - 96.

Mooney Simmie, G., Moles, J. \& O’Grady, E. (2019) Good teaching as a messy narrative of change within a policy ensemble of networks, superstructures and flows. Critical Studies in Education, 60(1), 55 - 72.

Nicol, D. (2013) Resituating feedback from the reactive to the proactive. In: Boud, D. \& Molloy, E. (Eds.) Feedback in higher and professional education. (pp. 34 - 49), Oxford, Routledge.

Nicol, D. (2010) From Monologue to Dialogue: Improving Written Feedback Processes in Mass Higher Education. Assessment \& Evaluation in Higher Education 35(5), 501-517.

Nilson, L.B. (2007) The graphic syllabus and the outcomes map: Communicating your course. San Francisco, Jossey-Bass.

Novak, J.D. (2010) Learning, creating, and using knowledge: concept maps as facilitative tools in schools and corporations. (2nd Edn.) Oxford, Routledge.

O’Donovan, B., Rust, C., \& Price, M. (2016) A scholarly approach to solving the feedback dilemma in practice. Assessment \& Evaluation in Higher Education, 41(6), 938-949

O'Leary, S. (2017) Graduates' experiences of, and attitudes towards, the inclusion of employability-related support in undergraduate degree programmes; trends and variations by subject discipline and gender. Journal of Education and Work, 30(1), 84 - 105.

Paxton, M. (2007) Tensions between textbook pedagogy and the literacy practices of the disciplinary community: A study of writing in first year economics. Journal of English for Academic Purposes, 6, 109 - 125.

Piaget, J., (1963). The origins of intelligence in children. New York: W. W. Norton.

Rolfe, G. (1996) Closing the theory-practice gap. Oxford, Butterworth.

Rootman-le Grange, I., \& Blackie, M. A. (2018). Assessing assessment: in pursuit of meaningful learning. Chemistry Education Research and Practice, 19(2), 484-490.

Rowe, C.M., Lahey, L., Kegan, R. \& Armstrong, E. (2003a) Questioning the ‘big assumptions'. Part 1: addressing personal contradictions that impede professional development. Medical Education, 37, 715 - 722.

Rowe, C.M., Lahey, L., Kegan, R. \& Armstrong, E. (2003b) Questioning the 'big assumptions'. Part 2: recognizing organizational contradictions that impede institutional change. Medical Education, 37, 723 - 733.

RCVS (2014) Setting Veterinary Standards. https://www.rcvs.org.uk/document-library/day-one-competences/

Salmon, D. \& Kelly, M. (2015) Using concept mapping to foster adaptive expertise: Enhancing teacher metacognitive learning to improve student academic performance. New York, Peter Lang.

Shay, S. (2013) Conceptualizing curriculum differentiation in higher education: A sociology of knowledge point of view. British Journal of Sociology of Education, 34(4), 563-582. 
Shay, S. \& Steyn, D. (2016) Enabling knowledge progression in vocational curricula: Design as a case study. In: Maton, K., Hood, S. \& Shay, S. (Eds.) Knowledge-building: Educational studies in legitimation code theory. London, Routledge.

Tai, J., Ajjawi, R., Boud, D., Dawson, P., \& Panadero, E. (2018) Developing Evaluative Judgement: Enabling students to make decisions about the quality of work. Higher Education, 76(3), 467-481.

Van Heuvelen, A. (1991). Learning to think like a physicist: A review of research based instructional strategies. American Journal of Physics, 59(10), 891-897.

van der Vleuten, C. Heeneman, S. Schuwirth, L. (2017) Programmatic Assessment In: JA Dent, RM Harden, D Hunt (Eds) A practical Guide for Medical Teacher. Edinburgh: Elsevier, 295-303.

Wheelahan, L. (2007) How competency-based training locks the working class out of powerful knowledge: A modified Bernsteinian analysis. British Journal of Sociology of Education, 28(5), 637-651.

Winstone, N. \& Carless, D. (2019). Designing effective feedback processes in higher education: A learningfocused approach. London: Routledge.

Winstone, N. E., Nash, R. A., Parker, M., \& Rowntree, J. (2017) Supporting learners' agentic engagement with feedback: A systematic review and a taxonomy of recipience processes. Educational Psychologist, 52(1), 17-37.

Winstone, N. and Pitt, E. (2017). Feedback is a two-way street. So why does the NSS only look one way? Times Higher Education Supplement [Online] 2323:30. Available at:

https://www.timeshighereducation.com/opinion/feedback-two-way-street-so-why-does-nss-only-look-one-way.

Young, M. \& Muller, J. (2013) On the powers of powerful knowledge. Review of Education, 1(3), 229 - 250.

Zajacova, K., Hepper, E. \& Grandison, A. (2019) Reconciling diverse student and employer voices on employability skills and work-based learning. In: Lygo-Baker, S., Kinchin, I.M. \& Winstone, N.E. (Eds.) Engaging Student Voices in Higher Education: Diverse Perspectives and Expectations in Partnership. (pp. 209 - 224) Cham, Switzerland, Palgrave Macmillan. 


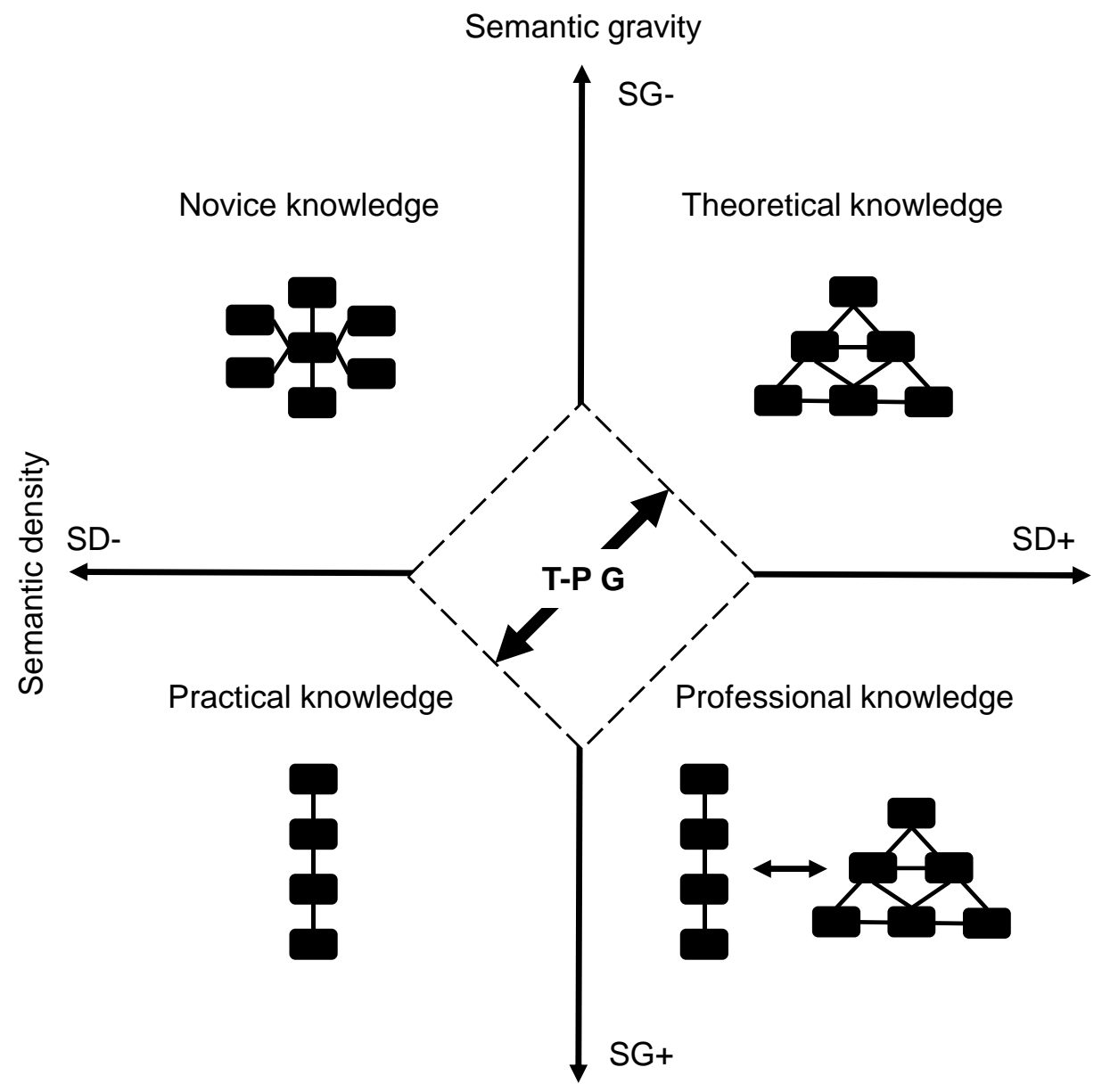

Figure 1: The semantic plane, showing the typical knowledge structures that may be found populating each of the quadrants. The possible separation of practical knowledge and theoretical knowledge is indicated by the presence of the theory-practice gap (T-P G) that will hinder progression from novice knowledge to professional knowledge by impeding semantic weaving across the plane (modified from Kinchin, 2016). 


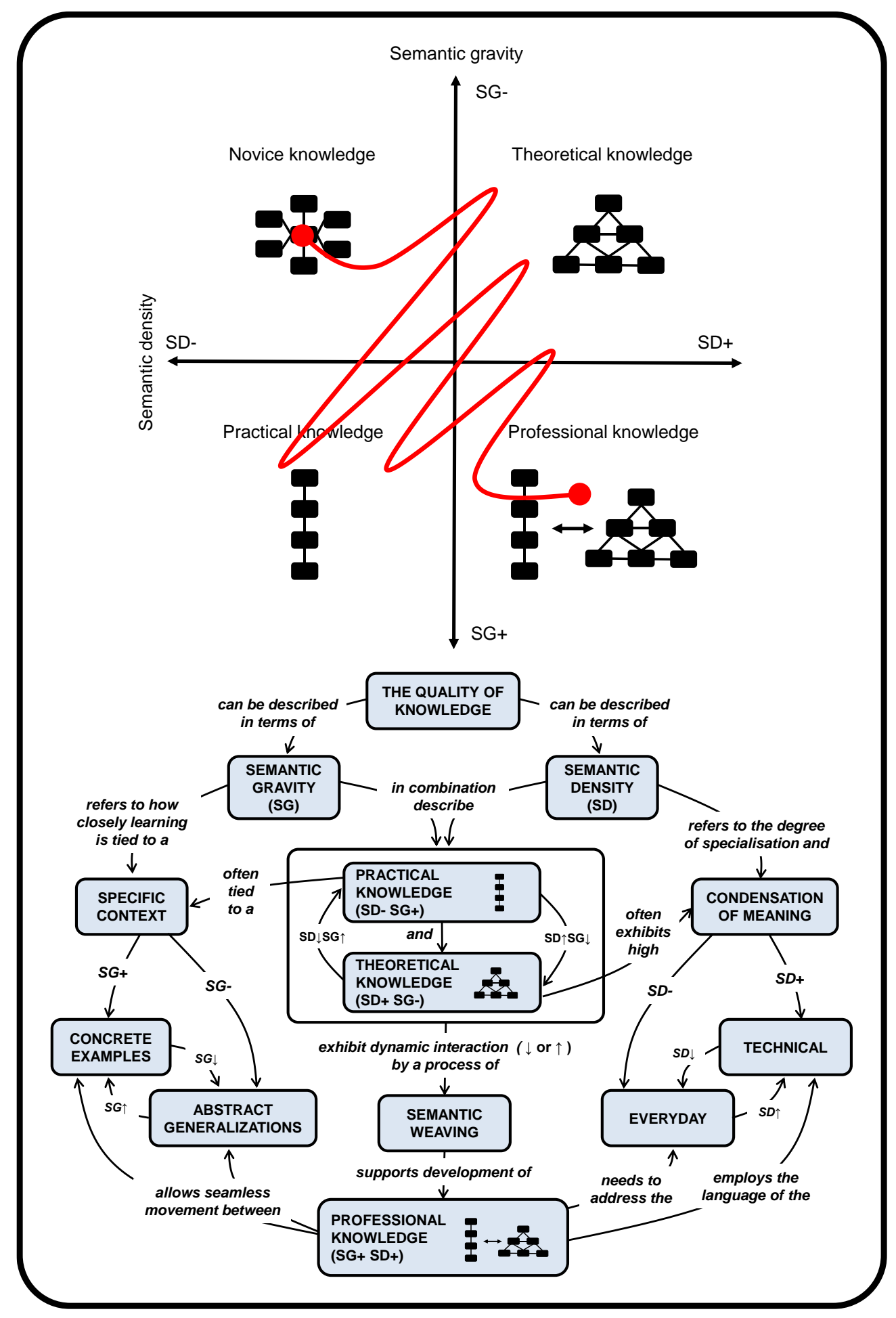

Figure 2: The semantic weaving between theoretical and practical knowledge that is required to move from a novice state towards professional knowledge. This is represented as a depiction of the semantic plane (above) and reinterpreted as a concept map (below). 


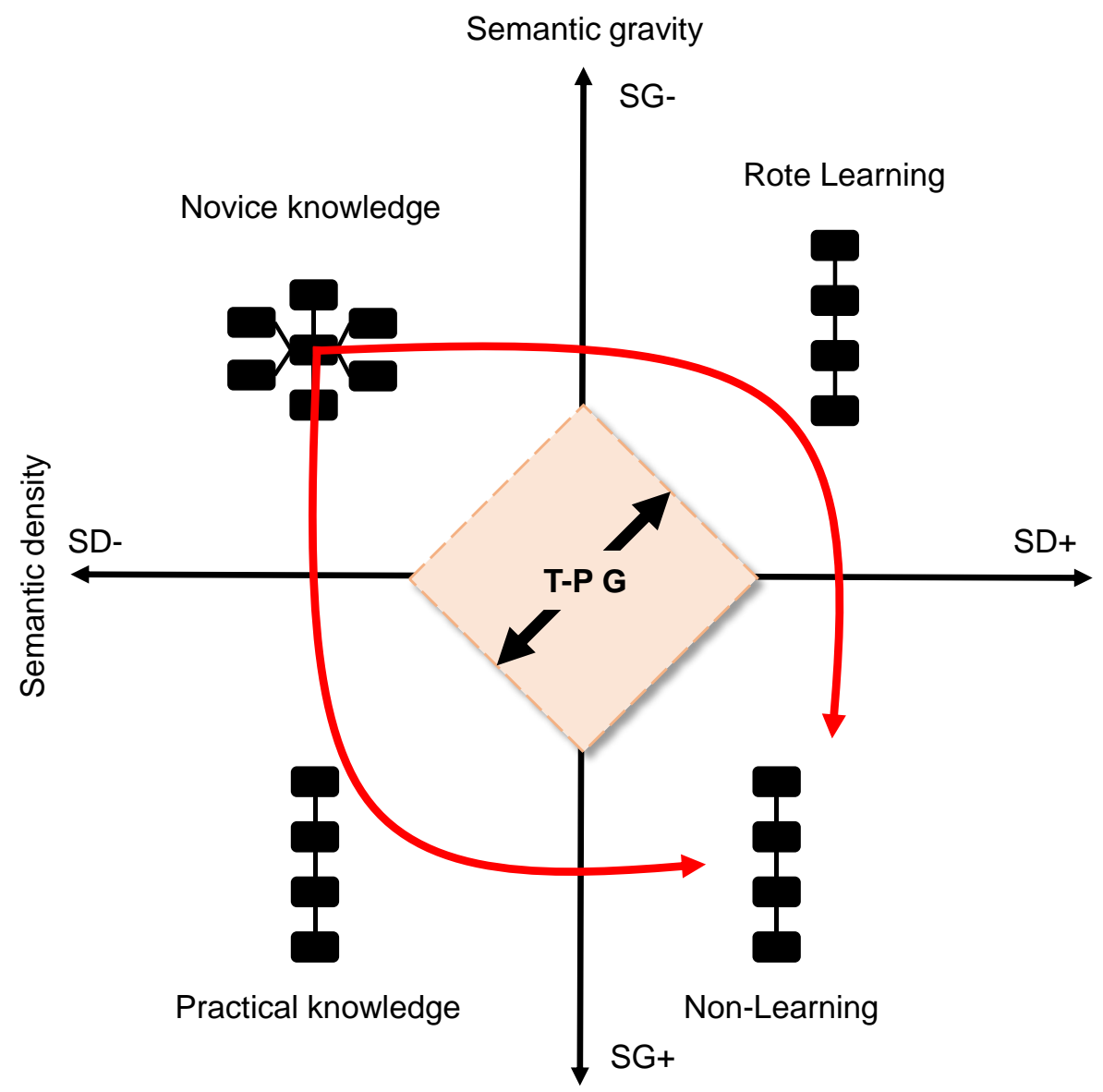

Figure 3: Where rote learning of theoretical knowledge results in a linear knowledge structure, a 'conceptual stand-off' is created across the theory-practice gap. This inhibits semantic weaving and results in non-learning and a failure to develop a professional knowledge structure. 